\title{
Influence of high cardiovascular risk in asymptomatic people on the duration and cost of sick leave: results of the ICARIA study
}

\author{
Eva Calvo-Bonacho ${ }^{1}$, Luis Miguel Ruilope², Miguel Angel Sánchez-Chaparro ${ }^{3}$, \\ Cesar Cerezo르, Carlos Catalina-Romero ${ }^{1 *}$, Paloma Martínez-Muñoz', \\ José R Banegas ${ }^{4}$, Bernard Waeber ${ }^{5}$, Arturo Gonzalez-Quintela ${ }^{6}$, and \\ Alberto Zanchetti ${ }^{7}$
}

\begin{abstract}
${ }^{1}$ Ibermutuamur (Mutua de Accidentes de Trabajo y Enfermedades Profesionales de la Seguridad Social 274), C/ Ramirez de Arellano, 27, 28043 Madrid, Spain; ${ }^{2}$ Hypertension Unit, Department of Nephrology, Hospital 12 de Octubre, Madrid, Spain; ${ }^{3}$ Hospital Virgen de la Victoria, and University of Malaga, Malaga, Spain; ${ }^{4}$ Department of Preventive Medicine and Public Health, School of Medicine, Universidad Autónoma de Madrid/IdiPAZ, CIBER of Epidemiology and Public Health, Madrid, Spain; ${ }^{5}$ Division of Clinical Pathophysiology and Clinical Research Centre, CHUV and University of Lausanne, Lausanne, Switzerland; ${ }^{6}$ Department of Internal Medicine, Complejo Hospitalario Universitario de Santiago, Santiago de Compostela, Spain; and ${ }^{7}$ Istituto Auxologico Italiano and University of Milan, Milan, Italy
\end{abstract}

Received 13 December 2012; revised 21 March 2013; accepted 11 April 2013; online publish-ahead-of-print 2 May 2013

See page 266 for the editorial comment on this article (doi:10.1093/eurheartj/eht178)

Aims

We investigated the potential influence of a moderate-to-high cardiovascular (CV) risk (CVR) (defined as a Systematic COronary Risk Evaluation model, or SCORE $\geq 4 \%$ ), in the absence of an established CV disease, on the duration and cost of $\mathrm{CV}$ and non-CV sick leave (SL) resulting from common and occupational accidents or diseases.

Methods We conducted a prospective cohort study on 690135 workers with a 1-year follow-up and examined CV-and non-CVand results related SL episodes. To obtain baseline values, CVR factors were initially assessed at the beginning of the year during routine medical examination. The CVR was calculated with the SCORE charts for all subjects. Moderate-to-high CVR was defined as SCORE $\geq 4 \%$. A baseline SCORE $\geq 4 \%$ was associated with a higher risk for long-term CV and non-CV SL, as revealed by follow-up assessment. This translated into an increased cost, estimated at $€ 5801464.18$ per year. Furthermore, pharmacological treatment for hypertension or hyperlipidaemia was significantly associated with longer SL duration.

Conclusion Moderate-to-high CVR in asymptomatic subjects was significantly associated with the duration and cost of CV and non-CV SL. These results constitute the first body of evidence that the SCORE charts can be used to identify people with a nonestablished CV disease, which might ultimately translate into more lost workdays and therefore increased cost for society.

Keywords Cardiovascular risk • Sick leave • Sickness absence • Work-related accidents

\section{Introduction}

An important component of the economic burden of cardiovascular (CV) disease is the loss of productivity due to $\mathrm{CV}$ morbidity and premature death. ${ }^{1}$ Several factors are known to delay the return to work following a CV event, increasing the cost of CV-related sick leave (SL). Indeed, many CV risk (CVR) factors (e.g. hypertension, ${ }^{2}$ smoking, ${ }^{3}$ diabetes, ${ }^{4}$ obesity, ${ }^{5}$ risk factors collectively known as 'metabolic syndrome,, and various health-related risk factors ${ }^{7}$ ) have been independently and positively associated with SL duration and the costs attributable to CV diseases. These data indicate that CVR factors could have a significant, deleterious economic impact even before overt CV disease is apparent. ${ }^{8}$ Therefore, the control of CVR factors through lifestyle modification and/or pharmacological intervention might not only help save lives, but may also reduce the direct and indirect costs incurred as a result of lost productivity. ${ }^{9-11}$

More than 5 million SL episodes are recorded annually in Spain, and the cost of providing temporary sick pay benefits exceeds $€ 6000$ million annually. ${ }^{12}$ Thus, SL analysis is valuable not only for estimating imputable costs, but also for identifying groups with increased health

* Corresponding author. Tel: + 3491 7445176, Fax: + 3491 4169699, Email: carloscatalina@ibermutuamur.es 
risks that are in need of targeted intervention. ${ }^{13}$ Routine medical examination provides an opportunity for early screening of workers for vascular risk factors and to select subjects with high CVR for more intensive intervention. ${ }^{14,15}$

In this context, we investigated the relationship between global CVR and the incidence, length, and cost of CV-disease-related SL. In addition, we examined the role of CVR in SL resulting from non-CV diseases and work-related accidents, which, to our knowledge, has never been investigated.

The aim of this study was therefore to investigate the relationship between global CVR, which was estimated using SCORE charts, ${ }^{16}$ and the 1-year incidence, length and cost of SL for CV-, non-CV-, or work accident-related reasons. Specifically, we analysed a large, representative sample of the Spanish workforce to gain a better understanding of the financial burdens associated with CVR in this group.

\section{Methods}

\section{Study design and participants}

This prospective cohort analysis was part of the ICARIA (Ibermutuamur CArdiovascular RIsk Assessment) study. ${ }^{15}$ Ibermutuamur is a mutual insurance company for work-related accidents and occupational illnesses that covers a population of approximately 1 million workers. Mutual insurance companies in Spain collaborate with National Social Security to administer statutory sick pay. Their responsibility also includes providing health care in the event of work-related accidents or occupational illnesses. In addition, a subsidiary company of lbermutuamur (Sociedad de Prevención de lbermutuamur) focuses specifically on preventing diseases and accidents by monitoring and promoting the health of workers through routine annual medical examination, among other things.

A total of 1441267 medical examinations were performed between May 2004 and December 2007. However, only data from each subject's first examination, containing all relevant CVR information, were considered in the present study. A total of 690135 subjects were included in this study $(71.6 \%$ male; mean ages: 36 for males and 34 for females; age range: 16-75). No significant socio-demographic differences (i.e. age, gender, occupational sector, and geographical distribution) were detected between workers who were included in the study and those who were not (data not shown). Importantly, this population was representative of the Spanish workforce. ${ }^{15}$ Records of physician-certified SL episodes over a 1-year period were obtained from the Social Security Register for $\mathrm{SL}$ due to common diseases and the lbermutuamur Register for SL due to work-related accidents. For SL episodes due to CV disease, the ICD- $9{ }^{17}$ codes $401-414$ and $426-443$ were considered, with the exception of codes 426.7, 429.0, 430.0, 432.1, 437.3, 437.4, and 437.5, which relate to non-atherosclerotic causes of death. This corresponds to endpoints defined in the SCORE project. ${ }^{16}$

The SCORE chart is the most widely used European CVR assessment tool and can be used to determine whether a subject is at high CVR (10-year risk of CV death is $\geq 5 \%$ ), moderate CVR (10-year risk of 4$4.9 \%$ ), or low CVR (10-year risk of $<4 \%) .{ }^{16,18}$ Additional information regarding risk factor measurement and CVR classification in the ICARIA study has been provided previously. ${ }^{15,18}$ Here, CV disease was defined as a clinically documented diagnosis of coronary, cerebrovascular, or peripheral arterial disease. Workers with type 1 or type 2 diabetes were excluded from this study.

The subjects were divided into two age groups ( $<45 \mathrm{vs}$. $\geq 45$, the latter representing approximately the upper 20th age percentile), and two occupational groups based on the Spanish National Classification of
Occupations [blue-collar (BC) workers and white-collar (WC) workers]. ${ }^{18}$ They were also classified according to smoking status (smoker vs. non-smoker). ${ }^{15}$

\section{Sick leave parameters}

All 690135 workers were monitored for 1 year after the date of their first medical examination. Incidence, duration (days), and contribution basis (in euro) were obtained for SL episodes caused by common CV-, non-CV-, or work accident-related reasons. The total number of SL days taken by each worker was then totalled and used as a dependent variable in analyses focused on SL duration.

\section{Ethical issues}

Signed informed consent was obtained from all participants before enrolment in the study, in accordance with the principles stated in the Declaration of Helsinki. The protocol was reviewed and approved by the local Ethics Committee.

\section{Statistical analysis}

All the statistical analyses were performed at the patient level. The annual incidence of at least one SL episode caused by common non-CV diseases, CV diseases, or work-related accidents was calculated separately in the overall cohort, and according to each variable considered (gender, age, occupation, smoking status, and CVR profile). Data were presented as percentages with $95 \%$ confidence intervals. A $\chi^{2}$ test was used to compare the SL incidence between the groups. The median and respective 25 th and 75 th percentiles were calculated for SL duration. The differences in median duration between groups were evaluated with the two-sample median test. Poisson regression was utilized for analysis of the association between CVR and SL duration. Crude and adjusted rate ratios (RRs) were calculated, adjusted by age, smoking status, or combined variables (gender, age, occupation, and smoking status). In addition, an over-dispersion correction for standard errors was performed. Furthermore, data were calculated separately for CV diseases, non-CV diseases, and work-related accidents. Categories with a lower median duration for all variables were used as the reference. Finally, the economic impact of longer SL durations in moderate-to-high CVR workers was estimated by multiplying the mean contribution basis of employees by the estimated increase in SL days in subjects with moderate-to-high CVR, and then by the number of workers in each SL group. Adjusted RRs were used to estimate the increase in SL days in moderate-to-high CVR with respect to the low CVR group, when such an association remained significant after entering covariates in the Poisson regression models. All analyses were performed using the SAS statistical package (SAS v. 9.1, SAS Institute, Inc., Cary, NC, USA).

\section{Results}

\section{Sick leave due to common non-cardiovascular diseases}

The incidence of SL caused by common non-CV diseases was $13.9 \%$, and the median duration of SL was 11 days (Table 1, Non-CV diseases). Both incidence and duration were higher in women than in men, in smokers than in non-smokers, and in BC than in WC workers. Age $\geq 45$ years was associated with a lower incidence but longer duration of SL. Workers with moderate-to-high CVR had an SL incidence that was not significantly different from low CVR individuals, but SL duration for moderate/high individuals was about twice as long (median duration 18 vs. 11 days, $P<0.0001$ ). 
Table I One-year incidence of at least one sick leave episode caused by common non-cardiovascular diseases, work-related accidents, cardiovascular diseases, and sick leave duration (days) in a cohort of 690135 workers (overall study population and data segmented by gender, age, smoking status, occupation, and cardiovascular risk profile)

\begin{tabular}{|c|c|c|c|c|c|}
\hline $\begin{array}{l}\text { Demographic, health, and } \\
\text { occupational variables }\end{array}$ & $\begin{array}{l}\text { Number of workers with at least } \\
\text { one sick leave episode }\end{array}$ & $\begin{array}{l}\text { Incidence }{ }^{a}(95 \% \\
\mathrm{Cl})\end{array}$ & $P$-value ${ }^{b}$ & $\begin{array}{l}\text { Median total duration } \\
(\text { P25;P75) }\end{array}$ & $P$-value \\
\hline \multicolumn{6}{|l|}{ Non-cardiovascular diseases } \\
\hline \multicolumn{6}{|l|}{ Gender } \\
\hline Male & 64871 & $13.1(12.1-14.05)$ & $<0.0001$ & $11(5 ; 28)$ & $<0.0001$ \\
\hline Female & 31376 & $16.1(14.4-17.7)$ & & $13(5 ; 39)$ & \\
\hline \multicolumn{6}{|l|}{ Age (years) } \\
\hline$<45$ & 80303 & $14.4(13.5-15.3)$ & $<0.0001$ & $10(5 ; 28)$ & $<0.0001$ \\
\hline$\geq 45$ & 15944 & $11.9(10.2-13.6)$ & & $18(7 ; 58)$ & \\
\hline \multicolumn{6}{|l|}{ Smoking status } \\
\hline Smoker & 51465 & $15.5(15.3-15.6)$ & $<0.0001$ & $11(5 ; 31)$ & 0.0014 \\
\hline Non-smoker & 44782 & $12.5(12.4-12.6)$ & & $11(5 ; 33)$ & \\
\hline \multicolumn{6}{|l|}{ Occupation } \\
\hline Blue collar & 66992 & $14.8(13.7-15.8)$ & $<0.0001$ & $11(5 ; 32)$ & 0.2636 \\
\hline White collar & 29255 & $12.2(10.9-13.5)$ & & $11(5 ; 32)$ & \\
\hline \multicolumn{6}{|l|}{ Cardiovascular risk profile } \\
\hline Moderate to high & 5391 & $12.8(9.6-15.9)$ & 0.42 & $18(8 ; 57)$ & $<0.0001$ \\
\hline Low & 90856 & $14.0(13.1-14.8)$ & & $11(5 ; 31)$ & \\
\hline Total & 96247 & $13.9(13.1-14.7)$ & & $11(5 ; 32)$ & \\
\hline \multicolumn{6}{|l|}{ Work-related accidents } \\
\hline \multicolumn{6}{|l|}{ Gender } \\
\hline Male & 40589 & $8.2(7.4-8.9)$ & $<0.0001$ & $11(6 ; 25)$ & $<0.0001$ \\
\hline Female & 6187 & $3.1(2.3-3.9)$ & & $13(7 ; 28)$ & \\
\hline \multicolumn{6}{|l|}{ Age (years) } \\
\hline$<45$ & 38634 & $6.9(6.2-7.6)$ & 0.04 & $11(6 ; 23)$ & $<0.0001$ \\
\hline$\geq 45$ & 8142 & $6.1(4.8-7.3)$ & & $14(7 ; 36)$ & \\
\hline \multicolumn{6}{|l|}{ Smoking status } \\
\hline Smoker & 27912 & $8.38(8.3-8.5)$ & $<0.0001$ & $11(6 ; 24)$ & $<0.0001$ \\
\hline Non-smoker & 18864 & $5.28(5.2-5.4)$ & & $11(6 ; 27)$ & \\
\hline \multicolumn{6}{|l|}{ Occupation } \\
\hline Blue collar & 42541 & $9.4(8.5-10.2)$ & $<0.0001$ & $11(6 ; 25)$ & $<0.0001$ \\
\hline White collar & 4235 & $1.7(1.2-2.3)$ & & $13(6 ; 29)$ & \\
\hline \multicolumn{6}{|l|}{ Cardiovascular risk profile } \\
\hline Moderate to high & 2940 & $6.9(4.5-9.4)$ & 0.46 & $13(7 ; 34)$ & $<0.0001$ \\
\hline Low & 43836 & $6.7(6.1-7.3)$ & & $11(6 ; 25)$ & \\
\hline Total & 46776 & $6.7(6.1-7.3)$ & & $11(6 ; 25)$ & \\
\hline \multicolumn{6}{|l|}{ Cardiovascular diseases } \\
\hline \multicolumn{6}{|l|}{ Gender } \\
\hline Male & 604 & $0.12(0.10-0.14)$ & $<0.0001$ & $101.5(31.5 ; 235)$ & 0.0011 \\
\hline Female & 77 & $0.04(0.03-0.05)$ & & $29(12 ; 153)$ & \\
\hline \multicolumn{6}{|l|}{ Age (years) } \\
\hline$<45$ & 252 & $0.05(0.03-0.07)$ & $<0.0001$ & $54(13 ; 149.5)$ & $<0.0001$ \\
\hline$\geq 45$ & 429 & $0.32(0.28-0.367)$ & & $122(39 ; 253)$ & \\
\hline \multicolumn{6}{|l|}{ Smoking status } \\
\hline Smoker & 380 & $0.11(0.09-0.13)$ & $<0.0001$ & $108.50(33 ; 249.50)$ & 0.0403 \\
\hline Non-smoker & 301 & $0.08(0.06-0.10)$ & & $74(19 ; 191)$ & \\
\hline \multicolumn{6}{|l|}{ Occupation } \\
\hline Blue collar & 502 & $0.11(0.09-0.13)$ & $<0.0001$ & $96(26 ; 250)$ & 0.3496 \\
\hline White collar & 179 & $0.08(0.06-0.10)$ & & $88(25 ; 174)$ & \\
\hline
\end{tabular}


Table I Continued

\begin{tabular}{|c|c|c|c|c|c|}
\hline $\begin{array}{l}\text { Demographic, health, and } \\
\text { occupational variables }\end{array}$ & $\begin{array}{l}\text { Number of workers with at least } \\
\text { one sick leave episode }\end{array}$ & $\begin{array}{l}\text { Incidence }{ }^{a}(95 \% \\
\mathrm{Cl})\end{array}$ & $P$-value ${ }^{b}$ & $\begin{array}{l}\text { Median total duration } \\
(\mathrm{P} 25 ; \mathrm{P} 75)\end{array}$ & $P$-value ${ }^{c}$ \\
\hline \multicolumn{6}{|l|}{ Cardiovascular risk profile } \\
\hline Moderate to high & 278 & $0.66(0.62-0.70)$ & $<0.0001$ & $111(36 ; 250)$ & 0.0218 \\
\hline Low & 403 & $0.06(0.04-0.08)$ & & $79(19 ; 201)$ & \\
\hline Total & 681 & $0.10(0.09-0.11)$ & & $92(26 ; 225)$ & \\
\hline
\end{tabular}

$95 \% \mathrm{Cl}, 95 \%$ confidence interval; P25;P75, 25th and 75th percentiles.

${ }^{a}$ Percentage of individuals with at least one sick leave episode.

${ }^{b} P$-value for $\chi^{2}$ test.

${ }^{c} P$-value for two-sample median test.

Non-CV diseases causing SL episodes were mainly: (i) diseases of the respiratory system (ICD 460-519); (ii) diseases of the musculoskeletal system and connective tissue (ICD 710-739); (iii) injury and poisoning (ICD 800-999); (iv) poorly defined conditions (ICD 780799); (v) infectious or parasitic diseases (ICD 001-139); (vi) diseases of the digestive system (ICD 520-579); (vii) mental disorders (ICD 290-319); (viii) and diseases of the nervous system and sense organs (ICD 320-389). In each of these conditions, the median SL duration was significantly longer in individuals with moderate-to-high CVR than with low CVR.

\section{Sick leave due to work-related accidents}

The overall incidence of SL caused by work-related accidents (6.8\%) was significantly lower than that caused by common non-CV diseases, but the median duration (11 days) was similar (Table 1, Workrelated accidents). The duration was slightly longer in women and individuals $\geq 45$ years, but not in smokers. On the other hand, BC workers had a slightly shorter median duration of SL. Moreover, moderate-to-high CVR was significantly associated with a longer median duration of SL due to work-related accidents.

\section{Sick leave due to common cardiovascular diseases}

As expected for the relatively young population of workers included in the ICARIA study, the incidence of SL caused by common CV diseases was very low $(0.10 \%)$, i.e. much lower than the incidence of $\mathrm{SL}$ due to non-CV diseases or to work-related accidents (Table 1, CV diseases). The occurrence of CV-related SL was significantly higher in men, individuals $\geq 45$ years, smokers, and BC workers. Moreover, the risk of SL due to CV disease for moderate-to-high CVR individuals, although rather low $(0.66 \%)$, was $>10$ times higher than for low CVR individuals $(0.06 \%, P<0.0001)$. On the other hand, the median duration of CV-related SL was notably long (92 days), and significantly longer in men, older workers, and smokers. The median SL duration was also significantly greater for individuals at moderate/ high CVR than for individuals at low CVR.

\section{Association with cardiovascular treatment}

As shown in Table 2, 26\% of workers with moderate-to-high CVR and $3 \%$ of those with low CVR were being treated for arterial hypertension and/or hyperlipidaemia. The median duration of SL caused by common
non-CV diseases or work-related accidents for these treated patients (both higher and lower CVR) was significantly longer than that of subjects without pharmacological treatment $(P<0.0001$ in all cases). A similar trend was observed for CV-related SL, but the difference did not reach statistical significance, likely because of the small sample size. Finally, pharmacologically treated patients were older than untreated ones, with the age difference small in the moderate-to-high CVR group $(54.5 \pm 7.5$ vs. $50.1 \pm 10.3 ; P<0.0001)$ and more pronounced in the low CVR group $(47.7 \pm 8.7$ vs. $34.1 \pm 9.7 ; P<0.0001)$.

\section{Role of associated variables}

The results of the Poisson regression analyses for the association of CVR with SL duration following covariate adjustment are presented in Table 3. Moderate-to-high CVR was associated with a significant increase in SL duration for CV or non-CV causes. Although the inclusion of age in the model reduced the magnitude of the estimated association between CVR and SL duration, the association remained significant for all three SL categories. Results from models that also adjusted for sex, occupation, and smoking status continued to reveal a significant association between CVR and SL duration for SL due to non-CV diseases and CV diseases, but no significant association for work-related accidents.

\section{Cost analysis}

Estimates of the additional costs associated with increased SL taken by individuals at higher CVR are summarized in Table 4. We estimated that the lengthened duration of non-CV-disease-related SL in individuals with moderate-to-high CVR amounted to additional costs of $€ 2151920.99$, and that $€ 3649543.19$ would be due to overt CV diseases, with a total additional cost of $€ 5801464.18$ during only the first year following initial medical examination.

\section{Discussion}

The most important and novel finding of this study is that moderate-to-high CVR was associated with an increased duration and cost of SL caused by common non-CV diseases.

A separate analysis of single CVR factors or patient characteristics demonstrated that many factors contributed to the increased duration of non-CV disease SL, confirming previously reported data. ${ }^{2-}$ ${ }^{8}$ However, in our study, even though gender, age, occupation, and 
Table 2 Number of workers with at least one sick leave episode caused by a common disease or work-related accident for non-cardiovascular reasons or due to cardiovascular diseases and sick leave duration in workers with moderate-to-high and low cardiovascular risk, with or without treatment for hypertension and/or hyperlipidaemia, in a cohort of 690135 workers with a 1-year follow-up

\begin{tabular}{|c|c|c|c|c|c|}
\hline Cardiovascular risk & $\begin{array}{l}\text { With or without } \\
\text { treatment }\end{array}$ & $\begin{array}{l}\text { Number of workers } \\
\text { with at least one } \\
\text { sick leave episode }\end{array}$ & $\begin{array}{l}\text { Median } \\
\text { total } \\
\text { duration }\end{array}$ & P25;P75 & $P$-value \\
\hline \multicolumn{6}{|l|}{ Common disease } \\
\hline Moderate to high & $\begin{array}{l}\text { With treatment } \\
\text { Without treatment }\end{array}$ & $\begin{array}{l}1393 \\
3998\end{array}$ & $\begin{array}{l}20 \\
18\end{array}$ & $\begin{array}{l}8 ; 64 \\
7 ; 53\end{array}$ & $<0.0001$ \\
\hline Low & $\begin{array}{l}\text { With treatment } \\
\text { Without treatment }\end{array}$ & $\begin{array}{r}2805 \\
88051\end{array}$ & $\begin{array}{l}17 \\
11\end{array}$ & $\begin{array}{l}7 ; 52 \\
5 ; 30\end{array}$ & $<0.0001$ \\
\hline \multicolumn{6}{|l|}{ Work-related accident } \\
\hline Moderate to high & $\begin{array}{l}\text { With treatment } \\
\text { Without treatment }\end{array}$ & $\begin{array}{r}652 \\
2288\end{array}$ & $\begin{array}{l}16 \\
13\end{array}$ & $\begin{array}{l}7 ; 39.5 \\
7 ; 33\end{array}$ & $<0.0001$ \\
\hline Low & $\begin{array}{l}\text { With treatment } \\
\text { Without treatment }\end{array}$ & $\begin{array}{r}1307 \\
42529\end{array}$ & $\begin{array}{l}13 \\
11\end{array}$ & $\begin{array}{l}6 ; 32 \\
6 ; 24\end{array}$ & $<0.0001$ \\
\hline \multicolumn{6}{|l|}{ Cardiovascular diseases } \\
\hline Moderate to high & $\begin{array}{l}\text { With treatment } \\
\text { Without treatment }\end{array}$ & $\begin{array}{l}125 \\
139\end{array}$ & $\begin{array}{l}106 \\
115\end{array}$ & $\begin{array}{l}36 ; 257 \\
36 ; 250\end{array}$ & 0.7121 \\
\hline Low & $\begin{array}{l}\text { With treatment } \\
\text { Without treatment }\end{array}$ & $\begin{array}{r}68 \\
308\end{array}$ & $\begin{array}{r}102 \\
73\end{array}$ & $\begin{array}{l}30 ; 239.5 \\
18.5 ; 184.5\end{array}$ & 0.2844 \\
\hline
\end{tabular}

$P 25 ; P 75,25$ th and 75th percentiles.

${ }^{\text {a }}$-value for two-sample median test.

Table 3 Crude and adjusted association between cardiovascular risk and sick leave duration caused by a common disease or work-related accident for non-cardiovascular reasons or due to cardiovascular diseases, calculated with a Poisson regression model (Poisson regression, stepwise adjusted model)

\begin{tabular}{|c|c|c|c|c|c|c|c|c|c|}
\hline \multirow[t]{2}{*}{ Cardiovascular risk } & \multicolumn{3}{|c|}{ Model I: crude } & \multicolumn{3}{|c|}{ Model II: adjusted by age } & \multicolumn{3}{|c|}{$\begin{array}{l}\text { Model III: adjusted by sex, age, } \\
\text { occupation, and smoking status }\end{array}$} \\
\hline & RR & $95 \% \mathrm{Cl}$ & $P$-value & $\mathbf{R} \mathbf{R}$ & $95 \% \mathrm{Cl}$ & $P$-value & $\mathbf{R R}$ & $95 \% \mathrm{Cl}$ & $P$-value \\
\hline \multicolumn{10}{|l|}{ Common disease } \\
\hline Moderate to high & 1.58 & $1.51-1.67$ & $<0.0001$ & 1.21 & $1.15-1.28$ & $<0.0001$ & 1.23 & $1.17-1.30$ & $<0.0001$ \\
\hline Low & 1 & & & 1 & & & 1 & & \\
\hline \multicolumn{10}{|l|}{ Work-related accident } \\
\hline Moderate to high & 1.43 & $1.32-1.54$ & $<0.0001$ & 1.23 & $1.14-1.34$ & $<0.0001$ & 0.97 & $0.90-1.04$ & 0.3855 \\
\hline Low & 1 & & & 1 & & & 1 & & \\
\hline \multicolumn{10}{|l|}{ Cardiovascular diseases } \\
\hline Moderate to high & 12.68 & $10.18-15.80$ & $<0.0001$ & 3.74 & $2.92-4.81$ & $<0.0001$ & 2.80 & $2.14-3.67$ & $<0.0001$ \\
\hline Low & 1 & & & 1 & & & 1 & & \\
\hline
\end{tabular}

$\mathrm{RR}$, rate ratio; $95 \% \mathrm{Cl}, 95 \%$ confidence interval.

Poisson regression model; $\mathrm{RR}<1$ indicates a shorter sick leave duration; $\mathrm{RR}>1$ indicates a longer sick leave duration.

smoking status were separately associated with SL incidence and duration, they did not completely account for the increased length of non-CV-related SL when global CVR was elevated. Thus, our results indicate that the SCORE charts identify workers with nonestablished CV disease that might contribute to increased lost workdays, and therefore higher cost for society. On the other hand, increased duration of SL due to work accidents in subjects with moderate-to-high CVR disappeared after adjusting for covariates.
To our knowledge, this prospective cohort study is the first to estimate the difference in costs associated with $\mathrm{SL}$ in workers with a moderate-to-high global CVR compared with those with a low CVR. Altogether, our study revealed an approximate increase in SL-associated cost (due primarily to SL caused by CV and non-CV common diseases in males) of $€ 5801464.18$ in the year after initial medical examination. When extrapolated to the total active Spanish workforce, this cost can be estimated at about $€ 145$ 


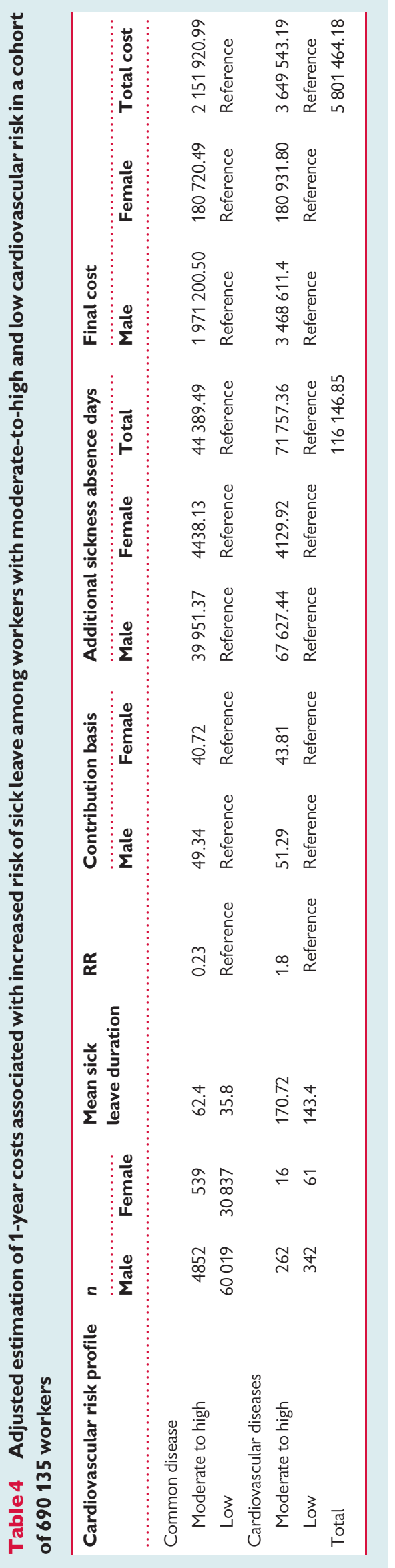

million per year. Moreover, our data estimated an increased cost associated with the early stages of CV disease in people with a SCORE $\geq 4 \%$, and indicated that these costs are partly unrelated to SL for CV disease. In addition to CV diseases, these heightened costs could result from increased SL caused by other types of non-CV diseases (e.g. respiratory, gastrointestinal, musculoskeletal, or infectious).

The reasons for this association between increased global CVR and longer duration of non-CV-related SL are unclear. The subjects included in the ICARIA study were relatively young (mean age of 36 years), and only $20 \%$ of them were $\geq 45$ years old. In addition, even those with a higher CVR level were unlikely to develop a consistent number of $\mathrm{CV}$ complications within the first year following initial examination, and this could explain the paucity of SL episodes attributed to CV diseases in the ICARIA cohort. Furthermore, some CVR factors, such as age and smoking, are also linked to a number of non-CV diseases. However, although these risk factors (especially age) appeared to play some role, adjusting for these and other CVR factors could not entirely account for the association between global CVR and non-CV disease SL duration. We can propose two distinct hypotheses that could explain this association. First, increased CVR may signify a broader general risk for common diseases, including non-CV-related illnesses, since higher CVR can indicate frailer individuals. This may be due to the fact that CVR is often associated with pro-inflammatory or pro-thrombotic states, ${ }^{19,20}$ which are also known to contribute to a number of non-CV diseases (e.g. respiratory diseases, musculoskeletal pathology, or infectious diseases). Thus, it is important to note that both CV diseases and a wide range of common non- $\mathrm{CV}$ diseases are rooted in the same clusters of health risk behaviours, which have become prominent in the Western world. Moreover, voluntary risk exposure, such as smoking, could be indicative of a risky personality type, and individuals who would regularly engage in such unsafe conduct may be more likely to be exposed to additional lifestyle-related hazards (e.g. risky sports, unsafe driving habits, and/or multiple sexual partners). ${ }^{21}$

A second hypothesis that could account for the association between CVR and non-CV-related SL duration involves a patient's growing awareness of their CVR. It is possible that becoming labelled as high risk for $\mathrm{CV}$ disease ultimately leads to a protective response in some individuals, who increase their number of SL episodes or elect longer SL durations. In this regard, we would like to point out that patients who were noted as having low or moderate/high CVR, and who were prescribed $\mathrm{CV}$ drug treatment (BP lowering or lipid lowering), had significantly longer SL due to non-CV diseases or work-related accidents. However, this observation is not entirely unexpected, as it is well known from prospective observational studies that hypertensive patients receiving treatment have a higher outcome incidence than untreated hypertensive patients, ${ }^{22-24}$ even though this directly contradicts data from controlled, randomized trials that consistently show outcome reduction by antihypertensive therapy. ${ }^{25}$ These discrepancies are thought to result from the fact that, in clinical practice, hypertensive patients are prescribed drug treatment when their global risk is elevated, whereas lower global risk hypertensive patients are often left untreated. This habit is consistent with the existing guidelines, ${ }^{26}$ and with the reimbursement policies of some national health services, which only reimburse antihypertensive drugs or statins to patients with a high global CVR. 
Indeed, in the ICARIA study, workers under CV treatment were older than untreated workers. However, among moderate-to-high CVR individuals, age difference was rather small (54 vs. 50 years), and is unlikely to be the main factor causing the difference in SL duration. It is, therefore, plausible that, in the ICARIA study, workers receiving CV drugs were in the upper part of the CVR range in which they had been classified, which obscured beneficial treatment effects and justified longer SL periods. Furthermore, regarding CVR awareness, receiving a drug prescription for $\mathrm{CV}$ reasons is likely to elicit a greater worry response from patients. Finally, but less probable, adverse effects due to drug treatment may lengthen SL duration.

In conclusion, our study shows that a higher level of CVR increases the duration of SL, due not only to CV diseases, but also to common non-CV diseases. Thus, CVR contributes to a marked increase in the financial burden resulting from SL, which we have calculated as $€ 5801464.18$ in 1 year for the 690135 workers included in our study. The obvious conclusion is that workplace preventive measures aimed at early control of $C V R^{27}$ may be widely beneficial in terms of health since they likely influence non-CV diseases as well. Ultimately, this could decrease the financial burden on society by reducing SL duration. Moreover, the notion that labelling a patient as higher CVR may cause concern, which consequently lengthens rather than reduces SL duration, should not deter prevention. Instead, this idea should promote the continued development of patient and employee education initiatives to communicate health information more precisely to workers. However, because our study was only observational, these inferences should be appropriately tested in an interventional study.

\section{Advantages and limitations}

The key advantages of this study were the prospective design, the sample size (approximately 700000 workers of both genders in all occupational sectors), and the analysis of various types of SL, namely those caused by non-CV diseases, CV diseases, and workrelated accidents.

Regarding study limitations, although the ICARIA cohort could be representative of the Spanish workforce, ${ }^{15}$ the generalizability of our results should be tested in other countries. Additionally, the SCORE charts present some limitations, such as overestimation of CVR in individuals $\geq 65$ years of age, underestimation of CVR in younger individuals, and exclusion of variables (e.g. family history of early onset coronary heart disease, impaired glucose tolerance, and hypertriglyceridaemia). Nevertheless, the SCORE charts are widely used to calculate CVR, and have been validated and calibrated in Spain. ${ }^{28}$

\section{Acknowledgements}

The authors wish to thank all the members of the ICARIA (Ibermutuamur CArdiovascular Rlsk Assessment) Study Group. ${ }^{15}$

\section{Funding}

The study was funded by a research project grant (FIS PI12/02812) from the Health Institute Carlos III and the Spanish Ministry of Economy and Competitiveness of Spain.

Conflict of interest: none declared.

\section{References}

1. Leal J, Luengo-Fernández R, Gray A, Petersen S, Rayner M. Economic burden of cardiovascular diseases in the enlarged European Union. Eur Heart J 2006;27: $1610-1619$.

2. Kiiskinen $U$, Vartiainen E, Puska P, Aromaa A. Long-term cost and life-expectancy consequences of hypertension. J Hypertens 1998;16:1103-1112.

3. Kiiskinen U, Vartiainen E, Puska P, Pekurinen M. Smoking-related costs among 25 to 59 year-old males in a 19-year individual follow-up. Eur J Public Health 2002;12:145-151.

4. Ramsey S, Summers K, Leong SA, Birnbaum HG, Kemner JE, Greenberg P. Productivity and medical costs of diabetes in a large employer population. Diabetes Care 2002; 25:23-29.

5. Neovius K, Johansson K, Kark M, Neovius M. Obesity status and sick leave: a systematic review. Obes Rev 2009;10:17-27.

6. Burton WN, Chen C-Y, Schultz AB, Edington DW. The prevalence of metabolic syndrome in an employed population and the impact on health and productivity.J Occup Environ Med 2008;50:1139-1148.

7. Tsai SP, Wendt JK, Ahmed FS, Donnelly RP, Strawmyer TR. Illness absence patterns among employees in a petrochemical facility: impact of selected health risk factors. J Occup Environ Med 2005;47:838-846.

8. Sullivan PW, Ghushchyan V, Wyatt HR, Wu EQ, Hill JO. Productivity costs associated with cardiometabolic risk factors clusters in the United States. Value Health 2007; 10:443-450.

9. Shultz AB, Edington DW. The association between changes in metabolic syndrome and changes in cost in a workplace population. J Occup Environ Med 2009;51: $771-779$.

10. Song X, Huse DM, Williams SA, Borock GM, McDonough K, Ozminkowski RJ. A projection of the impact of lipid-lowering therapy on high-risk employee disability and medical cost. J Occup Environ Med 2006;48:1014-1022.

11. Wolf M, Siadaty MS, Crowther JQ, Nadler JL, Wagner DL, Cavalieri SL, Elward KS, Bovbjerg VE. Impact of lifestyle intervention on lost productivity and disability control with activity and nutrition (ICAN). J Occup Environ Med 2009;51:139-145.

12. Sampere M, Gimeno D, Serra C, Plana M, Martínez JM, Delclos GL, Benavides FG. Organizational return to work support and sick leave duration: a cohort of Spanish workers with a long-term non-work-related sick leave episode. J Occup Environ Med 2011;53:674-679.

13. Head J, Ferrie JE, Alexanderson K, Westerlund H, Vahtera J, Kivimäki M. Diagnosisspecific sickness absence as a predictor of mortality: the Whitehall II prospective cohort study. BMJ 2008;337:a1469.

14. Lowe LP, Greenland P, Ruth KJ, Dyer AR, Stamler R, Stamler J. Impact of major cardiovascular disease risk factor, particularly in combination, on 22-year mortality in women and men. Arch Intern Med 1998;158:2007-2014.

15. Sánchez-Chaparro MA, Román-García J, Calvo-Bonacho E, Gómez-Larios T, Fernández-Meseguer A, Sáinz-Gutiérrez JC, Cabrera-Sierra M, García-García A, Rueda-Vicente J, Gálvez-Moraleda A, González-Quintela A. Prevalence of cardiovascular risk factors in the Spanish working population. Rev Esp Cardiol 2006;59: $421-430$.

16. Conroy RM, Pyörälä K, Fitzgerald AP, Sans S, Menotti A, De Backer G, De Bacquer D, Ducimetière $P$, Jousilahti $P$, Keil $U$, Njølstad I, Oganov RG, Thomsen $T$, Tunstall-Pedoe H, Tverdal A, Wedel H, Whincup P, Wilhelmsen L, Graham IM; SCORE project group. Estimation of ten-year risk of fatal cardiovascular disease in Europe: The SCORE project. Eur Heart J 2003;24:987-1003.

17. International Classification of Diseases. 9th Revision, Clinical Modification (ICD-9-CM). Geneva, Switzerland: World Health Organization; 1992.

18. Sánchez Chaparro MA, Calvo Bonacho E, González Quintela A, Cabrera M, Sáinz JC, Fernández-Labander C, Quevedo-Aguado L, Gelpi JA, Fernández Meseguer A, Brotons C, de Teresa E, González Santos P, Román García J; ICARIA (Ibermutuamur CArdiovascular Rlsk Assessment) Study Group. High cardiovascular risk in Spanish workers. Nutr Metab Cardiovasc Dis 2011;21:231-236.

19. Wijnstok NJ, TwiskJW, Young IS, Woodside JV, McFarlane C, McEneny J, Hoekstra T, Murray L, Boreham CA. Inflammation markers are associated with cardiovascular diseases risk in adolescents: the Young Hearts Project 2000. J Adolesc Health 2010; 47:346-351.

20. Karasek D, Vaverkova H, Halenka M, Jackuliakova D, Frysak Z, Slavik L, Novotny D. Prothrombotic markers in asymptomatic dyslipidemic subjects. J Thromb Thrombolysis 2011;31:27-36.

21. Eaton DK, Kann L, Kinchen S, Shanklin S, Flint KH, Hawkins J, Harris WA, Lowry R, McManus T, Chyen D, Whittle L, Lim C, Wechsler H; Centers for Disease Control and Prevention (CDC). Youth risk behavior surveillance - United States, 2011. MMWR Surveill Summ 2012;61:1-162.

22. Isles CG, Walker LM, Beevers GD, Brown I, Cameron HL, Clarke J, Hawthorne V, Hole D, Lever AF, Robertson JW. Mortality in patients of the Glasgow Blood Pressure Clinic. J Hypertens 1986;4:141-156.

23. Lindholm L, Ejlertsson G, Scherstén B. High risk of cerebrocardiovascular morbidity in well treated male hypertensives. A retrospective study of 40-59-year-old 
hypertensives in a Swedish primary care district. Acta Med Scand 1984;216: 251-259.

24. Benetos A, Thomas F, Bean KE, Guize L. Why cardiovascular mortality is higher in treated hypertensives versus subjects of the same age, in the general population. J Hypertens 2003;21:1635-1640.

25. Law MR, Morris JK, Wald NJ. Use of blood pressure lowering drugs in the prevention of cardiovascular disease: meta-analysis of 147 randomised trials in the context of expectations from prospective epidemiological studies. BMJ 2009;338:1665-1683.
26. National Institute for Health and Clinical Excellence (NICE). Hypertension. The clinical management of primary hypertension in adults. Clinical Guideline 127. 2011. www .nice.org.uk/guidance/CG127.

27. Laaksonen M, Piha K, Martikainen P, Rahkonen O, Lahelma E. Health-related behaviors and sickness absence from work. Occup Environ Med 2009;66: $840-847$.

28. Sans S, Fitzgerald AP, Royo D, Conroy R, Graham I. Calibrating the SCORE cardiovascular risk chart for use in Spain. Rev Esp Cardiol 2007;60:476-485.

\title{
CARDIOVASCULAR FLASHLIGHT
}

doi:10.1093/eurheartj/eht441

Online publish-ahead-of-print 17 October 2013

\section{Assessment of the vortex flow in the post-stenotic dilatation above the pulmonary valve stenosis in an infant using echocardiography vector flow mapping}

\author{
Takashi Honda ${ }^{1 \dagger}$, Keiichi Itatani2 ${ }^{2,3 * \dagger}$, Kagami Miyaji², and Masahiro Ishii ${ }^{1}$ \\ ${ }^{1}$ Department of Pediatrics, Kitasato University School of Medicine, Sagamihara, Kanagawa, Japan; ${ }^{2}$ Department of Cardiovascular Surgery, Kitasato University School of Medicine, \\ Sagamihara, Kanagawa, Japan; and ${ }^{3}$ Department of Hemodynamic Analysis, Kitasato University School of Medicine, Sagamihara, Kanagawa, Japan \\ * Corresponding author. Departments of Cardiovascular Surgery and Hemodynamic Analysis, Kitasato University School of Medicine, 1-15-1 Kitasato, Minami-ku, Sagamihara, \\ Kanagawa 252-0374, Japan. Tel: +81-42-778-8829, Fax: +81-42-778-8441, Email: keiichiitatani@gmail.com \\ † T.H. and K.I. contributed equally to this work.
}

A 15-month-old male diagnosed with double outlet right ventricle (DORV) suffered from right ventricular failure 8 months after DORV repair. The motion of the anterior cusp of the pulmonary valve (PV) after the commissurotomy of the bucuspid valve was poor on echocardiography, and computed tomography showed post-stenotic dilatation (Panels $A$ and $B$ ). We assessed the blood flow in the post-stenotic dilatation site of the main pulmonary artery (mPA) using echocardiography vector flow mapping (VFM). VFM is a new technology that makes it possible to visualize the flow velocity vector, and to calculate energy loss (EL) which results from the viscous dissipation in turbulent blood flow using colour Doppler mapping and speckle tracking and is thought to be the ventricular workload. The flow velocity vector analysis clearly showed that a large vortex formed from the posterior wall to the anterior wall just above the PV, and high EL was detected even though no pressure drop was detected by catheterization (Panels $C$ and $D$ ). After PV plasty with commissurotomy, the vortex diminished, resulting in a decrease of the mPA diameter. Additionally, the EL level at the mPA during the systolic phase considerably
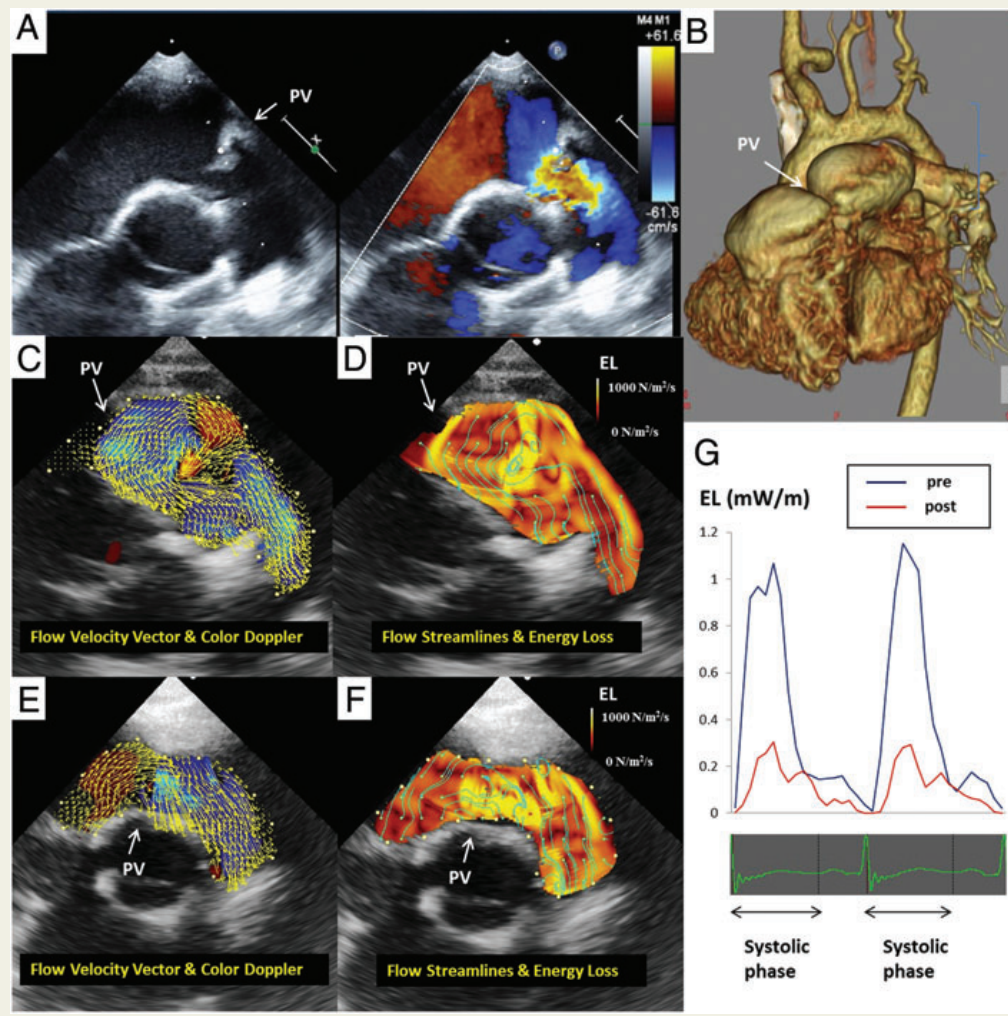

decreased after the procedure (Panels $E-G$ ). In the present case, the flow vector analysis visualized the abnormalities of blood flow above the PV stenosis. In addition, although further accumulation of such cases is warranted, EL would be a novel parameter that can be used to quantitatively evaluate the pressure overload for the ventricles caused by stenotic lesions.

Each author contributed to the care of the patient as well as the composition and review of the paper.

K.I. is the endowed chair of the Department of Hemodynamic Analysis, Kitasato University School of Medicine, and developed the VFM software with financial support from Hitachi-Aloka Medical Co., Ltd. K.M. is also financially supported by Hitachi-Aloka Medical Co., Ltd.

Supplementary material is available at European Heart Journal online. 